DOI: 10.14526/2070-4798-2019-14-4-54-60

\title{
The skills of qualified weightlifters' functional state control formation
}

\author{
Radmir V. Samigullin ${ }^{*}$, Ludmila D. Nazarenko', Oleg V. Shinkarenko ${ }^{2}$ \\ ${ }^{1}$ Ulyanov State Pedagogical University, Ulyanovsk \\ Ulyanovsk, Russia \\ ORCID: oooo-ooo1-6541-769X, r.samigullin1986@yandex.ru* \\ ORCID: oooo-ooo2-6225-6819, ld_nazarenko@mail.ru \\ ${ }^{2}$ Samara State Technical University \\ Samara, Russia \\ ORCID: oooo-ooo2-7848-5920, hoholava@mail.ru
}

\begin{abstract}
Sports achievements improvement is conditioned not only by the level of physical and technical readiness of an athlete, but also by functional indices. The state of cardiovascular, respiratory and other physiological systems conditions the character of adaptive transformations of an organism in terms of the training and competitive loads. Materials. The skills of the organism functional state control among qualified weightlifters is an urgent problem, the solution of which can be considered as one of the directions of sports training system development among those, who go in for kettlebell lifting. Research methods. Pedagogical experiment was held among cadets on the basis of the Air Force Academy Military Scientific Educational Center branch in Syzran. The aim of this research work was theoretical importance substantiation of control skills formation over the functional state of qualified weightlifters. Results. Important indices of an athlete's functional state doctors and coaches consider maximal oxygen consumption, the volume of arterial pressure, heart rate, minute blood volume and others. The methodology of control skills formation over functional systems activity included the following: respiratory system functions explanation; the importance of a rhythmic, deep breathing, motor and respiration rhythm coordination. The athletes mastered the data, which prove that good functional state of an organism. It is characterized by a gradual increase of vital capacity indices, maximum oxygen consumption. It gives an opportunity to control the character of this index change. Cardiovascular system determines the peculiarities of organism adaptation to the increasing training load. The qualified weightlifters measured heart rate and fill rate of pulse with the help of a stopwatch, analyzed ECG results. Conclusion. The skills of control formation over functional state helped to set necessary quantity of additional individual training load, kinds of physical exercises and also the conditions of their fulfillment for competitive exercises technique development. The results of the pedagogical experiment showed the effectiveness of created by us methodology of the control skills formation over physiological systems activity among qualified weightlifters.

Keywords: kettlebell lifting, cadets, functional indices, methodology.
\end{abstract}

For citation: Radmir V. Samigullin*, Ludmila D. Nazarenko, Oleg V. Shinkarenko. The skills of qualified weightlifters' functional state control formation. Russian Journal of Physical Education and Sport. 2019; 14(4): 46-51. DOI: 10.14526/2070-4798-2019-14-4-54-60 .

\section{INTRODUCTION}

Sports achievements improvement is conditioned not only by the level of physical and technical readiness of an athlete, but also by functional indices:heart rate, maximum oxygen consumption, lung ventilation, vital capacity and others. Under the influence of the training load the functions of respiration and blood circulation increase, kidneys and digestive system activity suppression, blood provision to not working organs decreases. It provides an athlete's working capacity increase. For successful sports activity it is necessary to take into consideration the peculiarities of vegetative reflexes change and appearancetheir ability to adapt to the definite kind of the training load. The specificity of vegetative organs functions, formed during mastering the technique of dumbbells lifting using different ways, presents different vegetative components of motor acts: cardiovascular, respiratory and others [3, 4].

Motor and vegetative components are formed not simultaneously: during physical exercises 
mastering with simple structural content first there is motor components formation; during techniques fulfillment with difficult structural content first of all vegetative components are formed. They provide rational respiration formation, motor and respiratory rhythm consistency increase, an optimal alternation of muscle tension and relaxation and etc.

After the technique of spurt mastering and after dumbbells push using two hands and the skill mastering vegetative components gain more steady inert features in comparison with motor ones. During the transfer from the dumbbells push to juggling motor functions quickly change their character and vegetative organs demand definite time to transform and they continue to function in previous regimen during some time period. That is why an athlete should include considerable changes into the structure of own sports activity during mastering new kinds of kettlebell lifting.

The aim of this research work is theoretical importance substantiation of control skills formation over the functional state of qualified weightlifters.

The objectives of the research:

1. To reveal the role of an athlete's functional state indices in the effectiveness increase of competitive activity.

2. To create the methodology of control skills formation over the physiological systems activity among people. They go in for kettlebell lifting and check its effectiveness during the pedagogical experiment.

\section{RESEARCH METHODS}

In order to check the effectiveness of the methodology, directed toward control skills formation over the functional state of qualified weightlifters, we held the pedagogical experiment. 24 qualified athletes (I and II category) at the age of 17-19 took part in the experiment. The control group (CG) and the experimental group (EG) were formed, each included 12 people. Before the pedagogical experiment the initial indices of functional state, physical and technical readiness were revealed. Functional indices were determined according to the following parameters: maximum oxygen consumption MOC (ml/min/kg), vital capacity VC
(1), arterial pressure AP (millimeter of mercury), heart rate HR (beats/min) after physical load (30squats); timed inspiratory capacity (s). In order to define physical readiness the following tests were used: shuttle running 3x10 cm;standing long-jump (cm); chin-up from hanging position (quantity); 100ometers running (min).

Technical readiness was estimated by the group of experts, qualified specialists in kettlebell lifting (5-point system), according to the following control exercises: formation level of individual motor rhythm; motor and respiratory rhythm consistency; rational distribution and redistribution of muscle efforts.

The initial indices of physical and technical readiness testing in the $\mathrm{CG}$ and the EG didn't reveal significant differences ( $p>0,05)$.

During continuous substances exchange different substances split into simple substances. During this process there is energy production. It is necessary for physiological processes, ruined cells reconstruction and new ones creation and also for tissues, hormones and enzymes formation. Owing to this energy an athlete fulfills physical load. Metabolism presents a difficult system of interconnected reactions of organic matters split and synthesis, as a result of which potential chemical energy is released. It provides the work of functional systems. The character of metabolism and energy is determined by neurohumoral system. Nervous system realizes its functions owing to incoming nervous impulses to tissues and to ductless glands. Metabolism change provides an athlete's organism adaptation to changing conditions of the training and competitive activity.

During training tasks fulfillment energy storage decreases. It is possible to define the amount of energy expenditure by means of the oxygen volume and the secreted carbonic acid measuring. The activity of a weightlifter demands considerable daily energy expenditure- till 50005500 (kcal), its volume is determined by the training level of the athlete, the degree of individual style of competitive exercises technique formation, age-related characteristics and others. Successful exercises fulfillment with dumbbells is conditioned by an optimal amount of oxygen income and timely 
breakdown products leading-out from the organism. Intensive muscle work is connected with the increase of oxygen consumption. During training tasks with dumbbells fulfillment more than three minutes the most rational is aerobic-anaerobic regimen with the transfer to aerobic by the end of the set by competitions rules of 10 minute part of time.

The results of competitive activity are mainly conditioned by the formation level of skills of pre-start and start state control; according to physiological mechanism the appearing before the start reactions are conditioned by specific and nonspecific reflexes. Specific reflexes are determined by the character of competitive load, non-specific ones by the degree of these competitions importance for the weightlifter. The intensity of these reactions is determined also by the conditions of competitions organization and holding, athlete's physical and technical readiness indices, the peculiarities of the type of his neural activity [5].

\section{RESULTS AND DISCUSSION}

During the pedagogical experiment we stated that among the qualified weightlifters (II and I categories) HR indices increased till 174-178 beats/min during the $4^{\text {th }}$ minute of competitive exercises fulfillment; during the $10^{\text {th }}$ minute the level of HR increases till 186-200 beats/min. For normal functional state preservation during sports competition it is important to take into consideration a rational rhythm of respiration and its coordination with motor one. In this connection special role has the warming-up. The main functions of warming-up are the following:

- irritability and lability of nerve centers increase as the condition of new time connections appearance while improving individual technique of exercises with dumbbells fulfillment;

- time period decrease between the start and the beginning of competitive exercises fulfillment;

- orientation improvement in competitive atmosphere and psycho-emotional state control in terms of the atmosphere change;

- bioactive substances activation: hormones, enzymes and the speed of biochemical reactions increase in the working muscles; their irritability and lability increase.
In kettlebell lifting during the push and spurt fulfillment because of heart work and respiration apparatus activation oxygen consumption increases, repository blood leading-out and its redistribution between the working and not working organs. An effective warming-up organization provides body temperature increase, which decreases muscles viscosity and the probability of traumatism. It is also important that the increased temperature creates necessary conditions for more intensive oxyhemoglobin dissociation in tissues. Conditioned by warming-up physiological changes in an organism improve an athlete's working capacity. In case of each further competitive exercise fulfillment lung ventilation achieves higher values. It is connected with vault-pathways phenomena in nerve centers. They provide more effective mobilization of respiration organs in case of further work. Competently organized warming-up provides successful adaptation of an organism to competitive activity.

Physiological systems adaptation to future work is realized by conditional way. In case of the increased intensity of muscles activity in inner environment become more distinct. At the same time, there is proprioceptive and interoceptive afference increase. It regulates the activity of an organism by reflex way. During competitive activity after 3-4 dumbbells pushes fulfillment using both hands from chest the activity of physiological systems becomes stable; oxygen consumption becomes constant. Minute blood volume and lung ventilation also achieve the indices. They are demanded for successful competitive exercises fulfillment.

During the work more active muscles get tired. In order to support their working capacity at an optimal level muscles relaxation is important after a strong tension. The peculiarities of the technique of dumbbells lifting include muscle tension and relaxation alternation. During dumbbells push using two hands first quadriceps of a hip is tense and then it is relaxed during dumbbells position stating above the head. During muscles relaxation their blood supply improves, intensive blood flow releases the working muscles from breakdown products.

Lifting dumbbells an athlete gets information from eyes receptors, vessels, vestibular apparatus, 
muscles proprioceptors, skin and etc., and it gives him an opportunity to feel the position of the separate parts of the body, dumbbells gravity influence, set motor and respiration rhythm. These senses provide specific "dumbbells sense" formation. It is Table 1 - Dynamics of functional indices among qualified weightlifters $\left(\mathrm{X}_{ \pm} \mathrm{Sx}\right)$

\begin{tabular}{|c|c|c|c|c|}
\hline \multirow[b]{2}{*}{ № } & \multirow[b]{2}{*}{ Indices } & \multicolumn{3}{|c|}{ Stages of pedagogical research } \\
\hline & & $\begin{array}{l}\text { Before the } \\
\text { pedagogical } \\
\text { experiment }\end{array}$ & $\begin{array}{c}\text { After the } \\
\text { pedagogical } \\
\text { experiment }\end{array}$ & $\begin{array}{c}\text { Increase } \\
\text { in } \%\end{array}$ \\
\hline 1 & $\mathrm{MOC} \mathrm{ml} / \mathrm{min} / \mathrm{kg}$ & $61,23 \pm 5,42$ & $\underline{61,82 \pm 4,81}$ & $\underline{1,01}$ \\
\hline 1 & 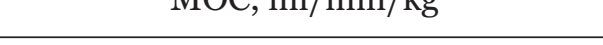 & $61,07 \pm 4,85$ & $62,37 \pm 5,35$ & 2,05 \\
\hline 2 & & $5,10 \pm 0,43$ & $5,23 \pm 0,39$ & 2,50 \\
\hline & $\mathrm{VC}(\mathrm{l})$ & $5,12 \pm 0,35$ & $5,81 \pm 0,42$ & $11,82^{*}$ \\
\hline 3 & AP ( millimeter of mercury ) & $121,4 \pm 10,33$ & $120,6 \pm 9,39$ & $\underline{0,66}$ \\
\hline & & $\frac{123,7 \pm 9,52}{76,37 \pm 5,10}$ & $\frac{121,5 \pm 11,83}{75,21 \pm 5,22}$ & $\begin{array}{l}1,78 \\
1,52\end{array}$ \\
\hline 4 & $\mathrm{HR}$ (beats/min) at rest & $7726+615$ & $7242+635$ & 408 \\
\hline 5 & HR (beats/min)after physical load (30 & $149,31 \pm 10,14$ & $147,22 \pm 10,41$ & 1,40 \\
\hline & squats) & $149,74 \pm 12,54$ & $146,51 \pm 12,13$ & 2,16 \\
\hline 6 & Timed inspiratory capacity (s). & $\begin{array}{l}51,29 \pm 4,53 \\
50,78 \pm 5,02\end{array}$ & $\begin{array}{l}53,18 \pm 3,89 \\
56,89 \pm 4,55\end{array}$ & $\begin{array}{c}3,50 \\
10,75^{*}\end{array}$ \\
\hline
\end{tabular}

Notes: in numerator - CG indices, in denominator- EG indices; indices validity in terms of significance level p<0,05

Breathing system provides gases exchange between the organism and environment, during which the working physiological systems get oxygen, necessary for energy production. Also carbon dioxide removal takes place. In order to strengthen respiration organs athletes from the EG trained in parks no less than three times a week, they were explained the importance of a rhythmic, even, deep breathing, motor and respiratory rhythms coordination. VC includes the following: breathing capacity, inspiratory reserve volume and expiratory reserve volume, an important functional index of respiration. It should correspond with height-weight indices, age and the training level of weightlifters. Athlete's good functional state is characterized by gradual increase of VC indices $[1,2]$. It helps an athlete to realize the control over their increase [6]. Blood circulation system determines organism adaptation to muscle load. In this connection an athlete should control HR, $\mathrm{AP}$ and other functional indices. HR and fill rate of pulse measurement is realized with the help of a stopwatch, that is why weightlifters from the EG at each training lesson controlled these indices, registered them in a diary of an athlete. Rhythmic pulse characterizes good work of heart. Apart necessary for an individual technique development; for accuracy improvement and timely muscle efforts distribution and redistribution; an optimal tempo of motor actions choice.

from everyday pulse control its rhythmicity was determined according to ECG. Minute blood volume (MBV) characterizes the state of blood circulation state, this index the athletes from EG determined according to Starr formula.

The skills of functional state control formation helped athletes to set individually the number of additional training load, kinds of the used physical exercises, their volume, conditions of fulfillment. Such an approach to sports training system organization provided not only weightlifters' functional state improvement in the EG, but also their physical and technical readiness indices increase. In the CG with the initial indices in chinups from hanging position $17,15 \pm 0,81$ times at the end of the pedagogical experiment indices improved

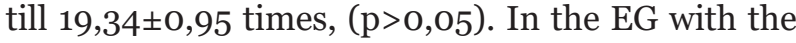
initial results $17,04 \pm 0,69$ times, at the end of the pedagogical experiment the results increased till $24,69 \pm 019$ times, $(p<0,05)$. In the $C G$ with the initial results in 1000 meters running $3,12 \pm 0,23 \mathrm{~min}$, at the end of the pedagogical experiment results were $2,94 \pm 0,20 \mathrm{~min},(\mathrm{p}>0,05)$; in the EG with the initial results $3,11 \pm 0,15 \mathrm{~min}$, at the end of the pedagogical experiment the results improved till 2,71 $\pm 0,19 \mathrm{~min}$, $(p<0,05)$. The same tendency of more significant 
physical readiness indices improvement among weightlifters from the EG was revealed according to other tests.

Technical readinessindices among the athletes from the $\mathrm{CG}$ and the EG during the pedagogical experiment changed in the following way: In the CG with the initial results in body steadiness during the work with dumbbells 3,12 $\pm 0,25$ points, at the end of the pedagogical experiment the indices improved till 3,26 $\pm 0,19$ points, $(p>0,05)$. In the EG with the initial results $3,14 \pm 0,29$ points, at the end of the pedagogical experiment the results increased till $3,78 \pm 0,17$ points, $(p<0,05)$. In the CG with the initial results in a rational muscles efforts distribution and redistribution $2,84 \pm 0,15$ points, at the end of the pedagogical experiment the results improved till 2,95 $\pm 0,21$ points ( $p>0,05$ ); In the EG with the initial results $2,81 \pm 0,20$ points, at the end of the pedagogical experiment the results increased till 3,34 $\pm 0,27$ points, $(\mathrm{p}<0,05)$. The same tendency of more considerable technical readiness indices improvement in the weightlifters from the EG was revealed according o other control exercises.

\section{CONCLUSION}

Thus, the results of the pedagogical experiment showed that the functional state improvement provides an athlete's working capacity increase, helps to realize the importance of the necessity to fulfill the training tasks independently in order to improve individual technique of competitive exercises with dumbbells fulfillment. They conditioned the increase of physical and technical readiness among the athletes from the experimental group.

\section{REFERENCES}

1. Vavilov V.V., Nazarenko

L.D. Physiological mechanism of body-building means influence on second adulthood men (40-49 yearsold). Pedagogiko-psychologicheskie I medicobiologicheskie problemy fizicheskoj kul'tury I sporta = Pedagogico-psychological and medicobiological problems of physical culture and sport. 2014; 2(31): 134-140. DOI: 10.14526/o0_1111_18 (In Russ., In Engl.)

2. Dyakova E.Yu., Mironov A.A. Adaptive system peculiarities of external respiration system among the athletes, who go in for finswimming. Teoriya I praktika fizicheskoj kul'tury = Theory and practice of Physical Culture. 2019; 11: 23-25 (In Russ., In Engl.).

3. Zimkin N. V. Fiziologiya cheloveka: uchebnik dlya institutiov fizicheskoj kul'tury [Physiology of a man: textbook for Physical Culture Institutes]. Moscow: Physical culture and sport. 2007 (In Russ.).

4. Nazarenko L.D. Fiziologiya fizicheskih uprazhnenij [Physiology of physical exercises]. Ulyanovsk: Federal State Budgetary Educational Establishment of Higher Education "Ulyanovsk State Pedagogical University”, 2017: 262 (In Russ.).

5. Samigullin R.V., Nazarenko L.D., Timoshkin V.V. Techniques modeling in kettlebell lifting. Pedagogiko-psychologicheskie I medicobiologicheskie problemy fizicheskoj kul'tury I sporta. 2008; 13(3): 66-74. URL: http:// journalsport.ru/images/vipuski/3-1/3.pdf (In Russ.).

6. Funina E.E., Frolov E.V. Metodologiya funkcional'nyh izmenenij sredi atletov razlichnoj kvalifikacii [Methodology of functional changes among the athletes of different qualifications]. Ulyanovsk. 2011: 63 (In Russ.).

7. Cox G.R., Desbrow B., Montgomery P.G., Anderson M.E., Bruce C.R., Macrides T.A. et al. Effects of different protocols of caffeine intake on metabolism and endurance performance. Journal of Applied Physiology. 2002; 93: 990-999.

8. Davis J.K., Green J.M. Caffeine and anaerobic performance: Ergogenic value and mechanisms of action. Sports medicine. 2009; 39: 813-832.

9. Smith A. Effects of caffeine in chewing gum on mood and attention. Human Psychopharmacology. 2009; 24: 239-247.

10. Souissi N., Bessot N., Chamari K., Gauthier A., Sesboue B., Davenne D. Effect of time of day on aerobic contribution to the 30-s Wingate test performance. Chronobiology International. 2007; 24: 739-748. 


\section{Submitted: 10.11.2019}

\section{Author's information:}

Radmir V. Samigullin - Post-graduate, Ulyanov State Pedagogical University, Ulyanovsk, 43270o, Russia, Ulyanovsk, Square of the $100^{\text {th }}$ anniversary of Lenin's birth, House 4, e-mail: r.samigullin1986@ yandex.ru

Ludmila D. Nazarenko - Doctor of Pedagogics, Professor, Ulyanov State Pedagogical University, Ulyanovsk, 43270o, Russia, Ulyanovsk, Square of the 1ooth anniversary of Lenin's birth, House 4, e-mail: ldnazarenko@mail.ru

Oleg V. Shinkarenko - Candidate of Pedagogics, Samara State Technical University, 44310o, Russia, Samara, Molodogvardeyskaya str., House 244, e-mail: hoholava@mail.ru 